\title{
Beta-Aminoisobutyric Acid as a Novel Regulator of Carbohydrate and Lipid Metabolism
}

\author{
Dmitrii A. Tanianskii ${ }^{1,2} \oplus$, Natalia Jarzebska ${ }^{3}$, Andreas L. Birkenfeld ${ }^{4}$, John F. O'Sullivan ${ }^{4,5}$ \\ and Roman N. Rodionov ${ }^{3, *}$ \\ 1 Department of Biochemistry, Institute of Experimental Medicine, Acad. Pavlov St., 12, \\ 197376 St. Petersburg, Russia; dmitry.athero@gmail.com \\ 2 Department of Fundamental Medicine and Medical Technology, St.Petersburg State University, 8 liter A, \\ 21st Line V.O., 199034 St. Petersburg, Russia \\ 3 University Center for Vascular Medicine, Technische Universität Dresden, Fetscherstraße 74, \\ 01307 Dresden, Germany; natalia.jarzebska@uniklinikum-dresden.de \\ 4 Medical Clinic III, Technische Universität Dresden, Fetscherstraße 74, 01307 Dresden, Germany; \\ andreas.birkenfeld@uniklinikum-dresden.de (A.L.B.); john.osullivan@sydney.edu.au (J.F.O.) \\ 5 Charles Perkins Centre and Heart Research Institute, The University of Sydney, 7 Eliza St, Newtown NSW, \\ Sydney 2042, Australia \\ * Correspondence: Roman.Rodionov@uniklinikum-dresden.de; Tel.: +49-351-458-3659
}

Received: 5 February 2019; Accepted: 26 February 2019; Published: 28 February 2019

\begin{abstract}
The prevalence and incidence of metabolic syndrome is reaching pandemic proportions worldwide, thus warranting an intensive search for novel preventive and treatment strategies. Recent studies have identified a number of soluble factors secreted by adipocytes and myocytes (adipo-/myokines), which link sedentary life style, abdominal obesity, and impairments in carbohydrate and lipid metabolism. In this review, we discuss the metabolic roles of the recently discovered myokine $\beta$-aminoisobutyric acid (BAIBA), which is produced by skeletal muscle during physical activity. In addition to physical activity, the circulating levels of BAIBA are controlled by the mitochondrial enzyme alanine: glyoxylate aminotransferase 2 (AGXT2), which is primarily expressed in the liver and kidneys. Recent studies have shown that BAIBA can protect from diet-induced obesity in animal models. It induces transition of white adipose tissue to a "beige" phenotype, which induces fatty acids oxidation and increases insulin sensitivity. While the exact mechanisms of BAIBA-induced metabolic effects are still not well understood, we discuss some of the proposed pathways. The reviewed data provide new insights into the connection between physical activity and energy metabolism and suggest that BAIBA might be a potential novel drug for treatment of the metabolic syndrome and its cardiovascular complications.
\end{abstract}

Keywords: BAIBA; myokines; AGXT2; obesity; metabolic syndrome; insulin resistance; AMPK; PPARs

\section{Introduction}

Manifestations of the metabolic syndrome such as abdominal obesity, dyslipidemia, insulin resistance, and hypertension, remain to be the major risk factors for diabetes and cardiovascular diseases. The mechanisms involved in pathogenesis of metabolic syndrome are still not fully understood. A prevailing hypothesis is that the expansion of abdominal fat mass, particularly in the visceral area, leads to "adiposopathy" and, as a result, to dysregulation of secretion of adipose tissue hormones and cytokines, named "adipokines" [1,2]. Obesity is commonly associated with increased production of adipokines, which induce insulin resistance and lipid disorders, such as tumor necrosis factor alfa (TNF $\alpha)$, resistin, and chemerin [3-7], and reduction of secretion of adipose tissue hormones 
with favorable effects on lipid and carbohydrate metabolism, such as adiponectin and omentin [8-10]. Leptin levels are elevated in obesity, but leptin's insulin sensitizing and anorexigenic effects are abrogated, due to resistance of target cells to the action of this hormone in this condition [11,12]. Interestingly, some adipokines that have beneficial effects on carbohydrate metabolism, such as visfatin, vaspin, and apelin, are paradoxically upregulated in obesity, possibly to partially compensate for the obesity-induced metabolic abnormalities [13-17].

The more recent hypothesis explains the development of obesity-associated metabolic disturbances through alteration in the production of myokines, or "exercise factors", by skeletal myocytes [18]. Secretion of these molecules, including interleukin (IL)-6, IL-15, and irisin, is strongly upregulated during aerobic physical exercise [18,19]. Acute 100-fold elevation of plasma IL-6 is potentially involved in improvement of glucose uptake and free fatty acids (FFA) oxidation by muscle cells during muscle contraction [18]. Elevation of IL-15 leads to a decline of fat mass in mice [20], and recently discovered myokine irisin induces "browning" of white adipose tissue (the differentiation of resident progenitor cells in white adipose tissue into morphologically and physiologically distinct brown-like adipocytes) and results in increased energy expenditure, body weight reduction, and improvement of diet-induced insulin resistance in mice [21].

More recently, $\beta$-aminoisobutyric acid (BAIBA), a non-protein amino acid secreted by skeletal muscles upon regular exercise via peroxisome proliferator-activated receptor gamma coactivator 1-alpha (PGC-1 $\alpha$ )-dependent mechanism, has been discovered as a novel endogenous protective myokine regulating adipose tissue browning, improving insulin sensitivity and protecting against a high-fat diet-induced obesity [22-24]. The goal of this review is to summarize the current knowledge about BAIBA metabolism and its recently discovered protective biological effects, and to discuss the implications of these recently discovered pathways for prevention and treatment of the metabolic syndrome and its complications.

\section{Production and Metabolism of BAIBA}

BAIBA was originally discovered in human urine in 1951 [25]. There are two enantiomers of BAIBA in biological systems: D-BAIBA (R-BAIBA) and L-BAIBA (S-BAIBA) [26,27]. The literature on the distribution of D-BAIBA and L-BAIBA in plasma, urine, and tissues is contradictory. While most of the studies suggest that D-BAIBA is the main enantiomer of BAIBA in the urine [26,28], some authors report L-BAIBA as the major enantiomer of BAIBA in plasma [26], while others claim that the more prevalent isoform is D-BAIBA [29]. D-BAIBA is produced in the cytosol from thymine in a metabolic pathway involving dihydropyrimidine dehydrogenase (DPYD), dihydropyrimidinase (DPYS), and $\beta$-ureidopropionase (UPB1) [30] and is further metabolized in mitochondria by alanine:glyoxylate aminotransferase 2 (AGXT2) to D-methylmalonate semialdehyde (D-MMS) [31] (Figure 1).

AGXT2 is a mitochondrial enzyme that uses pyridoxal phosphate as a cofactor and is present in the liver and also in epithelial cells of the kidney in the loop of Henle [32,33]. This enzyme has broad substrate specificity, the subject of which has recently been reviewed by our group [34]; however, the $\mathrm{Km}$ value for D-BAIBA at physiological $\mathrm{pH}(0.12 \mathrm{mM})$ is lower than for other amino donors, suggesting that D-BAIBA may be the preferred AGXT2 substrate [31].

L-BAIBA is generated from catabolic reactions of branched-chain amino acid L-valine [35,36] (Figure 1). Specifically, L-BAIBA is produced by the mitochondrial enzyme 4-aminobutyrate aminotransferase (ABAT) in the transaminase reaction between the downstream metabolite of L-valine L-methyl-malonyl semialdehyde (L-MMS) and L-glutamate [37-39]. ABAT is mainly expressed in the liver, brain, kidneys, muscles, and to a lower extent in the other tissues $[37,40]$. The optimal $\mathrm{pH}$ for this enzyme is 9.1, although it's also active at lower $\mathrm{pH}$ values [38]. Other amino acid substrates for ABAT ( $\mathrm{pH}$ 8.6) are $\gamma$-aminobutyric acid (GABA), $\beta$-alanine, $\delta$-aminovaleric acid, but not D-BAIBA or $\alpha$-amino acids [38]. The reaction of L-BAIBA production by ABAT is thought to be bidirectional, thus the same enzyme can also catalyze the conversion of L-BAIBA to L-MMS [37]. Both L-MMS and the metabolite of D-BAIBA D-MMS can be oxidized by methymalonate semialdehyde dehydrogenase (MMSDH) 
to propionyl-CoA [36]. Some amount of L-BAIBA is being converted to D-BAIBA, and vice-versa, through the stereo-isomerization reaction between L- and D-MMS [36,41]. The enzyme, which might be responsible for this reaction has not been found yet, while a nonenzymatic mechanism has also been proposed [41].

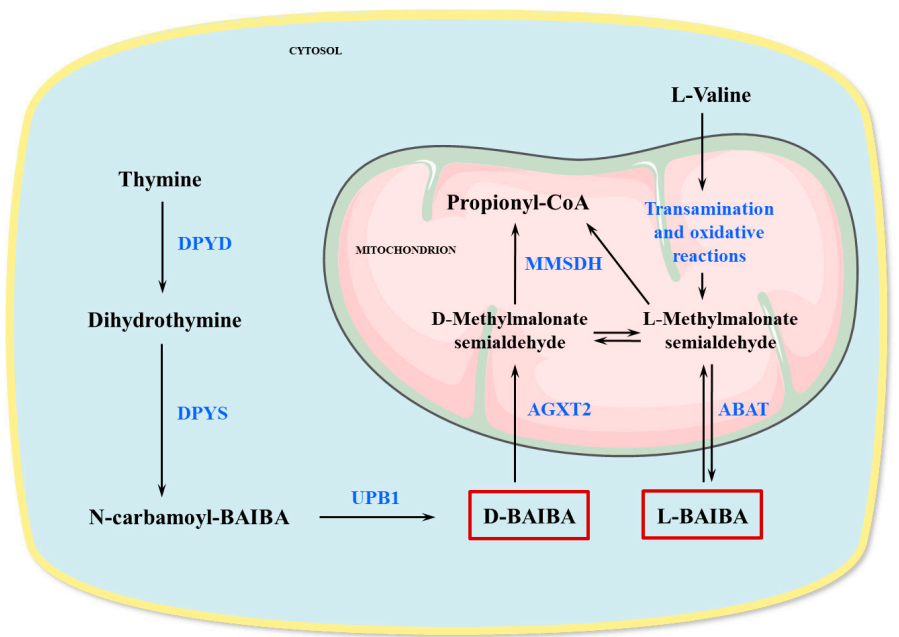

Figure 1. Production and metabolism of $\beta$-aminoisobutyric acid (BAIBA). D-BAIBA is produced in cytosole as an intermediate product of thymine degradation, while L-BAIBA comes from mitochondrial reactions of L-valine catabolism. Production and degradation of L-BAIBA is catalyzed by 4-aminobutyrate aminotransaminase (ABAT), a mitochondrial enzyme which is expressed mainly in the brain, kidney, liver, and muscles. D-BAIBA degradation also occurs in mitochondria with the participation of liver's and kidneys' enzyme alanine:glyoxylate aminotransferase 2 (AGXT2). The catabolic products of BAIBA enantiomers, L- and D-methylmalonate semialdehydes (L- and D-MMS), enzymatically oxidase with formation of propionyl-CoA. Some amount of L-BAIBA is being converted to D-BAIBA, and vice-versa, through the stereo-isomerization reaction between L- and D-MMS. DPYD—dihydropyrimidine dehydrogenase, DPYS-dihydropyrimidinase, UPB1- $\beta$-ureidopropionase, MMSDH—methymalonate semialdehyde dehydrogenase.

The regulation of systemic levels of D-BAIBA and L-BAIBA is still not entirely understood. It is known that patients with AGXT2 single nucleotide polymorphisms (SNPs) develop an autosomal recessive metabolic trait hyper-D- $\beta$-aminoisobutyric aciduria, which is characterized by elevation of D-BAIBA levels in plasma and urine [42,43]. Interestingly, this trait is presumed to be one of the most common metabolic traits in humans, affecting more than one third of certain Asian populations [44]. Roberts and colleagues reported that BAIBA levels were increased in plasma of mice after exercise-induced activation of PGC- $1 \alpha$, even though the authors did not measure D-BAIBA and L-BAIBA separately in their experiment [22]. Kitase and colleagues showed that production of L-BAIBA is increased during muscle contraction, presumably due to intensive oxidation of L-valine [45]. It is still unknown, whether systemic D-BAIBA levels are also affected by exercise or whether this regulation is only specific for L-BAIBA.

One of the major limitations in our understanding of the physiological effects of D-BAIBA and L-BAIBA is that most of the supplementation studies in animal models were performed with the D,L-BAIBA racemate, which makes it impossible to determine which of the BAIBA enantiomers were responsible for the observed effects.

\section{Metabolic Effects of BAIBA}

The initial discovery of the metabolic effects of BAIBA was made during mice studies investigating the effects of nucleoside reverse transcriptase inhibitors (NRTIs) on fat metabolism, in which it was shown that thymidine nucleosides and their intermediate product BAIBA, but not the other 
pyrimidines, increased hepatic FFA $\beta$-oxidation, ketone bodies production, and mRNA levels of the rate-limiting $\beta$-oxidation enzyme carnitine palmitoyltransferase 1 (CPT-1) in hepatocytes [46]. It was suggested that increased FFA oxidation through BAIBA might have been at least partially responsible for the cases of lipoatrophy of peripheral fat mass in human immunodeficiency virus infected patients receiving thymidine NRTIs $[47,48]$. Studies in murine models of obesity have shown that chronic treatment ( 2 weeks to 4 months) with BAIBA leads to a decline in body fat mass [22,23,48], induction of adipose tissue "browning" [22], increasing insulin sensitivity [22-24] and FFA oxidation [23,46,48] with lowering $[24,49]$ or neutral $[48,49]$ effects on plasma lipid levels, suggesting that the metabolic effects of BAIBA are not limited to the settings of the NRTI-induced peripheral fat loss. The major effects of BAIBA on lipid and carbohydrate metabolism and its signaling pathways are depicted in Figures 2 and 3.
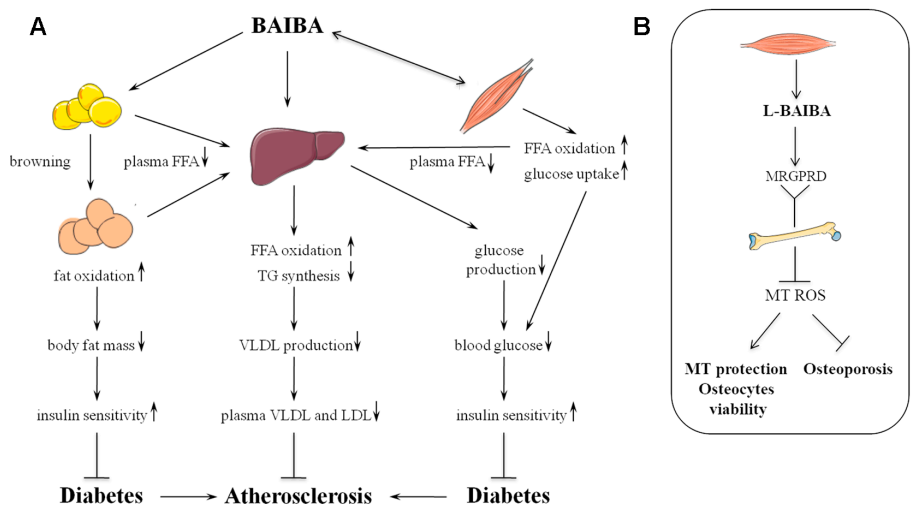

Figure 2. Proposed mechanisms of the biological effects of BAIBA. (A) Produced by skeletal myocytes and probably by other cell types, BAIBA regulates lipid and carbohydrate metabolism in fat tissue, liver, and skeletal muscles. BAIBA induces white to brown-like transformation of preadipocytes, which leads to an increase in fatty acids oxidation; it stimulates synthesis and/or activity of free fatty acids (FFA) oxidation enzymes in myocytes and hepatocytes as well. Together these processes lead to a lowering of plasma FFA level with subsequent decline in triglycerides (TG) synthesis and hepatic assembly of very low density lipoproteins (VLDL), the precursors of atherogenic low density lipoproteins (LDL) in the plasma. Decrease in body fat mass induced by adipose tissue "browning", together with stimulation of skeletal muscles' glucose uptake and down-regulation of hepatic glucose production enhance insulin sensitivity and reduce risk of diabetes and atherosclerosis. (B) L-BAIBA, but not its D-isoform binds to Mas-related G protein-coupled receptor type D (MRGPRD) on osteocytes. L-BAIBA diminishes reactive oxygen species (ROS) production in mitochondria (MT) and protects osteocytes from apoptosis, which results in prevention of bone loss [45].

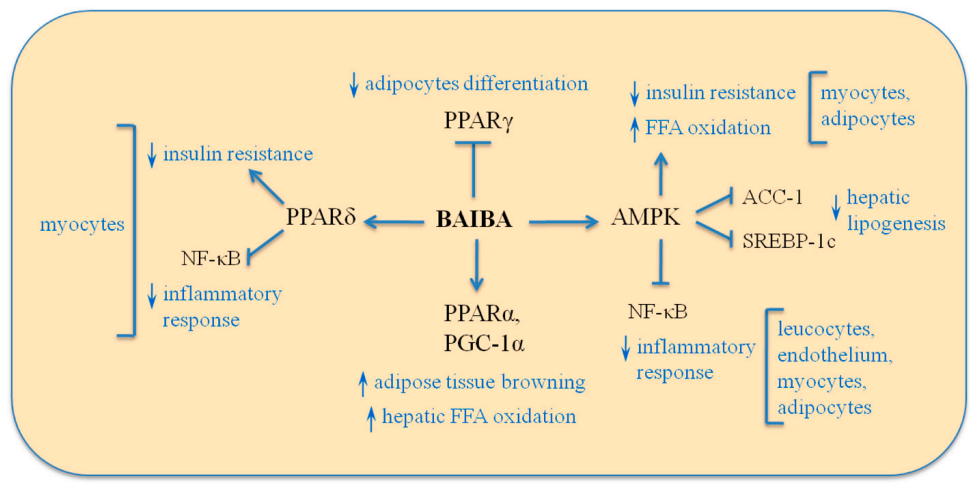

Figure 3. Signaling mediators of metabolic and anti-inflammatory effects of BAIBA. Multiple effects of BAIBA on metabolism and inflammation are mediated by activation of AMP-activated protein kinase (AMPK) and involvement of regulators of gene expression, such as peroxisome proliferator-activated 
receptors (PPAR) $\alpha / \delta / \gamma$, PPAR $\gamma$ coactivator $1 \alpha$ (PGC- $1 \alpha)$, as well as transcription factors Nuclear factor kappa B (Nf-kB) and Sterol regulatory element-binding protein-1c (SREBP-1c). ACC-1—acetyl-CoA carboxylase, FFA-free fatty acids.

\subsection{Adipose Tissue Browning}

BAIBA-induced body fat loss was not associated with changes in energy intake $[22,23,48]$ or physical activity in mice [22], however, it correlated with increased aerobic energy expenditure in these animals [22]. These data correspond well with the BAIBA stimulatory effects on FFA oxidation in the liver [22,46] and skeletal muscle cells [23], and on the oxygen consumption by adipose tissue and hepatocytes [22]. Moreover, Roberts et al., 2014 found that BAIBA stimulated differentiation of white adipose tissue preadipocytes to a beige or, so called "brite" (brown in white) phenotype under in vivo and in vitro conditions. BAIBA induced gene expression of the mitochondrial uncoupling protein UCP-1, mitochondrial biogenesis transcription coactivator PGC- $1 \alpha$, and respiratory chain protein cytochrome $\mathrm{c}$ in differentiating adipocytes [22]. These effects were dependent on peroxisome proliferator-activated receptor (PPAR) $\alpha$, the nuclear receptor, and major transcription activator of FFA oxidation and brown adipose tissue metabolism [22,50]. Increased fatty acids combustion, together with lowering of ATP production efficiency via uncoupling mechanisms, could be an explanation for the decreased body fat accumulation induced by BAIBA.

Adipose tissue browning may also improve plasma lipid profiles and blood glucose levels. Indeed, increased uptake of plasma nutrients such as glucose, triglycerides (TG)-rich very low density lipoproteins (VLDL), and FFA by cold-activated brown adipose tissue in mice was associated with a decline of plasma TG levels and increased insulin sensitivity [51]. The question remains, however, whether browning of white adipose tissue, particularly induced by BAIBA, leads to similar effects on lipid and carbohydrate metabolism, which are observed during activation of the "classic" brown adipocytes and if this explains the observed weight loss.

\subsection{Lipid Metabolism and Insulin Sensitivity}

Interestingly, even though BAIBA treatment in lean mice increased ketogenesis, an indicator of increased hepatic FFA oxidation, it did not alter plasma lipid parameters including FFA, TG, total cholesterol, and phospholipids concentrations [48]. Moreover, the hepatic TG content also did not decrease. One potential explanation for these results could have been an upregulation of lipolysis in adipocytes as a compensation mechanism to overcome decreased FFA levels. Compensatory increase in FFA delivery to hepatocytes may have preserved hepatic TG synthesis and lipoprotein formation after activation of FFA oxidation. Begriche et al., 2008 reported that incubation of mouse adipocytes with $3 \mathrm{mM}$ BAIBA did not affect glycerol production [49], which supports the hypothesis that lipolysis could be an indirect compensatory effect, rather than a direct effect of BAIBA.

BAIBA treatment also had no effect on plasma lipid parameters in mice with high-fat diet-induced obesity or in obese leptin-deficient $o b / o b$ mice [48,49], but led to a decline in postprandial levels of TG and fasting cholesterol levels in $o b /+$ mice with partial leptin deficiency [49], and reduced fasting FFA, TG, and low density lipoproteins (LDL) cholesterol levels in high-fat diet/low-dose streptozotocin model of type 2 diabetes mellitus in mice [24]. Hypolipidemic effects of BAIBA in the last two models were associated with decreased hepatic lipogenesis and improvements in insulin sensitivity [24,49], while these effects were not observed in $o b / o b$ mice [49]. The authors speculated that the observed effects of BAIBA might have been at least partially leptin-dependent, because these effects disappeared in the model of complete leptin deficiency.

Currently, it is not known whether BAIBA has direct effects on hepatic triglyceride synthesis and lipid oxidation. Studies in vitro have produced contradictory results, with PPAR $\alpha$-dependent up-regulation of CPT-1 and acyl-CoA oxidase mRNA [22] and no effect on palmitate oxidation in response to treatment of cultured hepatocytes with BAIBA [49]. Interestingly, BAIBA stimulated phosphorylation of AMP-activated protein kinase (AMPK) in human hepatoma HepG2 cells in 
glucosamine-induced endoplasmic reticulum (ER)-stress settings, but not in the control glucosamine free cells [24]. Phospho-AMPK is the active form of the enzyme AMPK, which phosphorylates and inhibits the key enzyme of de novo TG synthesis acetyl-CoA carboxylase and up-regulates CPT-1 activity due to lowering concentration of its inhibitor malonyl-CoA [52]. Moreover, AMPK down-regulates expression of fatty acids synthesis enzymes via phosphorylation and inactivation of the transcription factor SREBP-1c [53]. Animal data suggest that ER stress in hepatocytes is provoked by hepatic excess lipid accumulation and insulin resistance [54]. Activation of AMPK by BAIBA during ER stress may be favorable for lipid metabolism, reducing lipid accumulation and apolipoprotein B (apoB)-containing lipoproteins production in hepatocytes [24]. Future studies will reveal, whether there is any impact of BAIBA on lipogenesis in hepatocytes at the basal conditions or in the settings of ER stress.

Another possible mechanism of hypolipidemic effects of BAIBA observed in some murine models above is modulation of insulin resistance. It is known that improvement of insulin sensitivity has a favorable impact on plasma lipid profile due to insulin-mediated decline in circulating FFA levels and insulin's blunting effects on hepatic production of apoB-containing lipoproteins [55]. According to Jung and coauthors, 10-30 $\mu \mathrm{M}$ BAIBA decreased palmitate-induced insulin resistance in mouse C2C12 myocytes and lipopolysaccharides (LPS)-induced insulin resistance in mouse 3T3 adipocytes, together with an increase in glucose uptake and activation of FFA oxidation enzymes expression in both cell types $[23,56]$. These effects were mediated through activation of AMPK $[23,56]$ and were also dependent on PPAR $\delta$ in the muscle cells [23]. BAIBA also decreased expression of gluconeogenic enzymes and increased phosphorylation of insulin receptor substrate IRS-1, kinase Akt, as well as AMPK in the livers of mice with experimental type 2 diabetes mellitus induced by high-fat feeding and low-dose streptozotocin treatment [24]. Plasma insulin levels in that study were not changed, which suggests that BAIBA increased insulin sensitivity without influence on insulin secretion, but the question remains whether BAIBA has a direct action on insulin signaling in hepatocytes.

\subsection{Adipokines and Cytokines}

There is a possibility that some of the metabolic effects of BAIBA are mediated by other circulating signaling molecules. Begriche and coauthors reported that BAIBA stimulated leptin production in $o b /+$ mice with partial leptin deficiency, but not in wild type mice with normal circulating leptin levels [49]. It is well known that leptin plays a pleiotropic role in human and mouse metabolism, including body weight stabilization (through inducing satiety signaling in the brain and upregulating thermogenesis), increasing FFA oxidation and insulin sensitivity, and decreasing hepatic TG production; these effects are partially mediated through AMPK stimulation [12,57]. Interestingly, BAIBA was metabolically active in mice with partial leptin deficiency, but not in wild type mice with normal leptin production or $o b / o b$ mice with total depletion of this hormone. These results suggest that BAIBA may affect lipid metabolism and insulin sensitivity via restoration of leptin levels in patients with reduced production of this hormone [49]. It is estimated that about $5-10 \%$ of obese individuals are low leptin secretors [58]. The reasons for the selective effects of BAIBA on leptin secretion in $o b /+$, but not in +/+ adipocytes, are not currently known. Leptin production in adipocytes is partially modulated by negative feedback mechanisms through leptin-mediated activation of the sympathetic nervous system $[59,60]$. Potentially, a local negative feedback regulation of leptin synthesis and/or secretion exists in adipocytes. Therefore, this may explain the limited effect of BAIBA on leptin production in adipocytes with normal leptin content, but the robust one in adipocytes with insufficient leptin synthesis.

Several studies reported that BAIBA can downregulate production of proinflammatory cytokines, which are increased during the chronic low-grade inflammation in adipose tissue seen in obesity [23, 56,61-63]. Specifically, BAIBA treatment led to declines in plasma levels of TNF $\alpha$ in mice with high-fat diet-induced obesity [23]. Moreover, BAIBA downregulated palmitate-induced IL-6 gene expression in murine $\mathrm{C} 2 \mathrm{C} 12$ myocytes [23], decreased LPS-stimulated TNF $\alpha$ production by adipocytes and mononuclears [56,63], and inhibited LPS-induced monocytes adhesion on endothelium [63]. Those effects were mediated by AMPK-dependent inhibition of nuclear factor kappa B and were 
also dependent on PPAR $\delta$ in skeletal muscle cells $[23,56,63]$. Using genetic or chemical cytokines modulation approaches will be crucial for revealing the role of this anti-inflammatory action of BAIBA on adiponectin production in obesity as well as on insulin resistance, lipid metabolism, and atherosclerosis. Interestingly, even though $\mathrm{TNF} \alpha$ inhibits production of adiponectin, which is an adipokine, favorably regulating lipid and carbohydrate metabolism $[8,64]$, effects of BAIBA on adiponectin production or its plasma levels could not be demonstrated experimentally $[22,48,49]$. Future studies will have to address the relative contribution of the effect of BAIBA on the specific cytokines and adipokines towards the overall protective metabolic effects of BAIBA.

\subsection{Signaling Mechanism}

The mechanisms, through which BAIBA acts on cell metabolism, are still obscure. Several membrane receptors for BAIBA were proposed, including $G$ protein-coupled receptors (GPRs), such as Mas-related GPR type D (MRGPRD) [45,65] and orphan receptor GPR41 [22,49] as well as ligand-gated ion channel receptors for glycine and GABA [66,67].

MRGPRD is mainly localized in neurons of dorsal root ganglia, but its expression is also found in the urinary bladder, testis, uterus, arteries, and bone cells $[45,68]$. L-BAIBA is more potent than D-BAIBA for prevention of age-induced osteocytes death, and this effect is mediated via the MRGPRD receptor, which also binds $\beta$-alanine and GABA $[45,65]$. Specificity of MRGPRD for D-BAIBA as well as stereospecificity of BAIBA enantiomers towards other potential receptors has not been evaluated.

BAIBA may act on adipocytes through activation of GPR41, another G-protein coupled receptor expressed in different cell types, but predominantly in white adipocytes $[49,69,70]$. This receptor is activated by short chain fatty acids, including propionate, butyrate, pentanoate, and isobutyrate, but not by GABA [70], making it possible that BAIBA also acts as a ligand. Propionate and BAIBA similarly activated leptin secretion by adipocytes [49], and the effect of propionate, like of other small fatty acids, was mediated by GPR41 [70]. Effective concentration at EC50 for this effect of propionate and butyrate was around $200 \mu \mathrm{M}$, which is comparable with their concentrations in peripheral blood, 50-100 $\mu \mathrm{M}$ [70]. However, if BAIBA potentially activates these receptors with similar efficiency, it would likely not have a strong effect in vivo, since in this case the circulating concentration of BAIBA would be two orders of magnitude lower than its EC50.

There are data suggesting that BAIBA, like other $\beta$-amino acids such as $\beta$-alanine, taurine, and $\beta$ aminobutyrate, binds to and activates glycine receptors [66]. Besides the brain, these receptors are localized in many somatic cells including macrophages, lymphocytes, endotheliocytes, cardiomyocytes, hepatocytes, and renal cells, where they mediate the anti-inflammatory, immunomodulating, anti-ischemic, and cytoprotective effects of glycine [71]. Moreover, glycine intake had some metabolic effects on sucrose-fed animals, stimulating octanoate $\beta$-oxidation, reducing plasma FFA and TG, and reducing intraabdominal fat accumulation [72]. However, it seems unlikely that the metabolic effects of BAIBA are mediated through its action on the glycine receptors due to the differences in the agonist concentration and activity between glycine and BAIBA. Plasma concentration of BAIBA (about $2 \mu \mathrm{M}$ ) is about 100-fold lower than the plasma concentration of glycine, which is around $200 \mu \mathrm{M}$ [73], and BAIBA, like other $\beta$-amino acids studied, has a smaller agonist activity for the glycine receptor than its $\alpha$-amino acid ligand glycine [66].

Finally, $\beta$-alanine, taurine and, possibly, BAIBA, also activate the GABA receptors [67]. Like the glycine receptors, the receptors for GABA are expressed not only in the central nervous system, but also outside the brain, e.g., in hepatocytes, endocrine, and immune cells, modulating cell proliferation and immune response [74-76]. It is not known whether GABA has a metabolic impact, but there is a probability that BAIBA, the GABA isomer, acts through the peripheral GABA receptors.

In addition to membrane receptor activation, other pathways of BAIBA signaling may include transport of this molecule inside the cell through specific transport proteins such as the taurine transporter (TauT) selective for $\beta$-amino acids [77]. Once internalized, BAIBA may activate cytoplasmic or nuclear receptors with subsequent modulation of gene expression, influence on allosteric regulation 
of metabolic enzymes or undergo conversion into biologically active compounds, e.g., peptides or chemical modifications. Some effects of BAIBA may be mediated through its binding to AGXT2 that results in competitive inhibition of metabolism and leads to concurrent elevation of other substrates of this enzyme such as asymmetric dimethylarginine (ADMA), symmetric dimethylarginine (SDMA) [33], and homoarginine [78], which impact the cardiovascular system and metabolism [79-82]. Hopefully, future studies will decipher the actual BAIBA signaling mechanism.

\section{Human Implications}

In a large human cohort study $(n=2067)$, plasma levels of BAIBA correlated inversely with plasma concentrations of glucose, insulin, TG, and total cholesterol [22]. These results are in accordance with the positive impacts of BAIBA on adiposity, insulin resistance, and lipid parameters in mice described earlier [22-24]. At the same time, these studies do not prove the causality of BAIBA action in human metabolism; one of the approaches to assess causality is to perform genetic investigations. The rs37370 (c.506T>C, Asn102Ser) AGXT2 SNP has been associated with elevation of circulating BAIBA levels, decreased cholesterol esters plasma content, and, surprisingly, with increased plasma TG levels [83]. The reasons for the contrasting relationship of the analyzed AGXT2 SNPs and BAIBA concentrations with plasma TG are not known. AGXT2 knockdown in zebrafish also led to an increased TG/cholesterol ester ratio, but plasma BAIBA levels were unexpectedly decreased [83]. These data hint that AGXT2 affects lipid metabolism independent from BAIBA, possibly via elevation or reduction of the other substrates of this enzyme. However, replication of the findings from Rhee et al., 2013 [83] will still be required in other populations or clinical groups, and the influence of other AGXT2 SNPs on lipid metabolism and insulin sensitivity will need to be tested. Furthermore, AGXT2 only metabolizes D-BAIBA, thus AGXT2 polymorphisms' studies do not address potential metabolic effects of L-BAIBA.

Spitsyn and Afanas'eva showed in 2001 the elevated urine excretion of BAIBA in patients with coronary atherosclerosis [84]. The AGXT2 C-A-A-A haplotype (rs37370, rs37369, rs180749, rs16899974) in the Japanese population has been positively associated with both BAIBA urine excretion and carotid intima-media thickening [85]. Meanwhile, it is not known whether this haplotype has an impact on other AGXT2 substrates such as ADMA, SDMA [34], as well as homoarginine [78]. Interestingly, elevated plasma levels of ADMA and SDMA are linked to a poor cardiovascular prognosis [79,86], while homoarginine concentration negatively correlates with cardiovascular disease outcomes [80, 87]. These observations tell us about the complexity of the influence of AGXT2 genetic variants on atherosclerosis and vascular biology, as it depends on ratio between different AGXT2 substrates in plasma and in the individual tissues. The impact of AGXT2 polymorphisms on its biologically active substrates depends not only on the Km of AGXT2 for those substrates, but also on the activity of the alternative metabolic pathways for those compounds. Thus, AGXT2 SNP rs37369 and, to lesser extent, rs16899974, were associated with elevation of plasma levels of BAIBA and SDMA, while ADMA, arginine, and homoarginine levels were unchanged $[43,88]$. In spite of influence on SDMA systemic levels, these polymorphisms were not associated with cardiovascular mortality [88,89], although patients with rs16899974 showed an increased incidence of ischemic stroke [90]. These results might be possibly explained by potential protective effects of BAIBA, which may compensate for the negative impact of SDMA on atherosclerosis progression (Figure 4). Future studies could test this possibility by determining, whether BAIBA has any direct protective effects on atherosclerosis. 


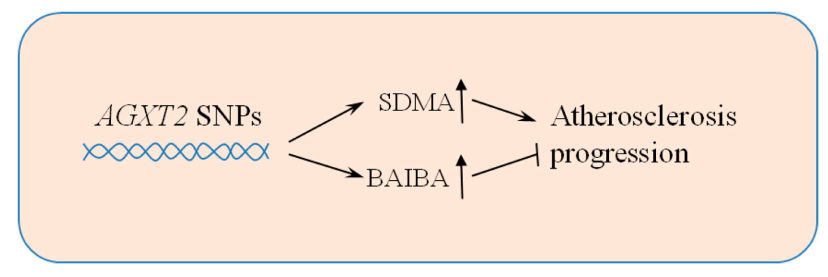

Figure 4. Potentially protective effect of BAIBA on atherosclerosis progression in human subjects with functional AGXT2 SNPs. AGXT2 functional SNPs associate with elevation in plasma concentration of both its substrates, SDMA and BAIBA, that oppositely affect atherosclerosis development and cardiovascular outcomes in humans. AGXT2—alanine:glyoxylate aminotransferase 2, SNPs—single nucleotide polymorphisms, SDMA—symmetric dimethylarginine, BAIBA- $\beta$-aminoisobutyric acid.

\section{Future Directions}

One of the major challenges in understanding the physiological and pathophysiological roles of BAIBA is that we are actually dealing with two separate potentially highly biologically active compounds D-BAIBA and L-BAIBA, with different metabolism and different downstream effects. Since most of the available epidemiological and experimental studies do not distinguish between those compounds, it is unclear which of these two compounds is responsible for the observed effects. It is also possible that in some studies opposite effects of D-BAIBA and L-BAIBA cancel each other out, giving misleading results, which are difficult to interpret. One of the major directions of future research will be to systematically determine the relative contribution of D-BAIBA and L-BAIBA to the already discovered effects of BAIBA.

The currently available literature proposes BAIBA as a powerful endogenous regulator of metabolism in humans. BAIBA elevation due to prolonged physical exercise or genetic polymorphisms may be favorable for body fat mass, plasma lipoproteins levels, insulin sensitivity, inflammatory responses, and possibly for the arterial wall. However, the physiological role of BAIBA is still unknown. It may be playing a role as an "exercising factor" similar to IL-6 or irisin $[18,19]$, but the relevance of the effects of these substances during regular exercise for human health and metabolism still needs to be determined. Future studies with muscle-specific downregulation of IL-6, irisin, or BAIBA production, will reveal their significance for metabolic responses during regular exercise.

It is known that physical activity leads to increased FFA turnover due to activation of lipolysis in adipose tissue and FFA oxidation in muscles; a similar change in FFA metabolism occurs in diabetes. It appears that the metabolic effects of BAIBA occur primarily in conditions of FFA-induced insulin resistance [23,24]. Possible functions of BAIBA in this case may be to overcome the increasing amounts of FFA and insulin resistance in patients with diabetes and abdominal obesity. Therefore, there should be some regulation of BAIBA production under the control of FFA or glucose and insulin. Roberts et al., 2014 revealed that the transcriptional coactivator PGC- $1 \alpha$, which is induced in muscles by physical exercise, stimulates BAIBA production, possibly through expression of enzymes responsible for valine catabolism [22]. However, FFA and insulin both downregulate PGC-1 $\alpha$ activity by attenuating its RNA synthesis and phosphorylation [91]. Downregulation of PGC-1 $\alpha$ is also associated with mitochondrial dysfunction, which is seen in a diabetic state [92]. Future investigations of the impact of FFA, insulin, hyperglycemia, as well as mitochondrial dysfunction on BAIBA production in muscles and other tissues will help to elucidate whether BAIBA plays a role in overcoming the elevation of plasma FFA and glucose in diabetes. Alternatively, declining production of BAIBA under these conditions can amplify metabolic derangements in diabetic patients. It will also be of interest to check, if BAIBA production is sensitive to the local milieu of cytokines, myokines, and adipokines (e.g., TNF $\alpha$, IL-6, irisin, adiponectin, and leptin), which also modulate FFA metabolism and insulin sensitivity.

An additional question for future research is the relevance of the metabolic and anti-inflammatory effects of BAIBA $[23,56,63]$ on the development of metabolic syndrome and atherosclerosis in humans. To evaluate whether BAIBA is involved in all these spectra of metabolic disturbances in humans, 
additional population studies will be required comparing BAIBA plasma concentration and AGXT2 functional SNPs with severity of atherosclerosis, obesity, diabetes, and metabolic and inflammatory plasma markers. Finally, intriguing questions remain regarding the mechanisms responsible for the metabolic and anti-inflammatory effects of BAIBA. The discovery of its receptor or enzymes modulated by BAIBA will not only unveil the physiological role of this amino acid, but also provide an opportunity to design novel drugs for the treatment of obesity, diabetes, dyslipidemia, and atherosclerosis.

\section{Conclusions}

Interventional studies in mice as well as the results, obtained in cell culture models and human cohorts have demonstrated a novel function of the non-protein amino acid BAIBA-its involvement in regulation of carbohydrate and lipid metabolism. Particularly, BAIBA declines body fat mass, increases insulin sensitivity, favorably affects lipid metabolism, and also decreases inflammatory reactions. It seems that BAIBA preferentially acts in FFA overload conditions, such as physical activity and diabetes. Future research is needed to clarify if dysregulation of BAIBA production and/or its action is involved in pathogenesis of obesity, diabetes, dyslipidemia, and atherosclerosis. The relevance of BAIBA's specific isomers and recently identified L-BAIBA receptor as well as other potential BAIBA receptors for the signaling effects of this amino acid also need to be determined.

Author Contributions: Conceptualization, D.A.T. and R.N.R.; reviewing the literature, D.A.T., N.J., and R.N.R.; original draft preparation, D.A.T. and N.J.; review, editing, and final content of the manuscript, A.L.B., J.F.O., and R.N.R.; all authors discussed the data, read, revised, and approved the final manuscript.

Funding: This research was supported by the DAAD scholarship (award 57210733) and Dresden Fellowship Program-2017 to D.A.T.

Conflicts of Interest: The authors declare no conflict of interest.

\section{References}

1. Després, J.P.; Arsenault, B.J.; Côté, M.; Cartier, A.; Lemieux, I. Abdominal obesity: The cholesterol of the 21st century? Can. J. Cardiol. 2008, 24, 7D-12D. [CrossRef]

2. Van De Voorde, J.; Pauwels, B.; Boydens, C.; Decaluwé, K. Adipocytokines in relation to cardiovascular disease. Metabolism 2013, 62, 1513-1521. [CrossRef] [PubMed]

3. Hotamisligil, G.S.; Shargill, N.S.; Spiegelman, B.M. Adipose expression of tumor necrosis factor- $\alpha$ : Direct role in obesity-linked insulin resistance. Science 1993, 259, 87-91. [CrossRef] [PubMed]

4. Steppan, C.M.; Bailey, S.T.; Bhat, S.; Brown, E.J;; Banerjee, R.R.; Wright, C.M.; Patel, H.R.; Ahima, R.S.; Lazar, M.A. The hormone resistin links obesity to diabetes. Nature 2001, 409, 307-312. [CrossRef] [PubMed]

5. Costandi, J.; Melone, M.; Zhao, A.; Rashid, S. Human resistin stimulates hepatic overproduction of atherogenic ApoB-containing lipoprotein particles by enhancing ApoB stability and impairing intracellular insulin signaling. Circ. Res. 2011, 108, 727-742. [CrossRef] [PubMed]

6. Bozaoglu, K.; Bolton, K.; McMillan, J.; Zimmet, P.; Jowett, J.; Collier, G.; Walder, K.; Segal, D. Chemerin is a novel adipokine associated with obesity and metabolic syndrome. Endocrinology 2007, 148, 4687-4694. [CrossRef] [PubMed]

7. Sell, H.; Laurencikiene, J.; Taube, A.; Eckardt, K.; Cramer, A.; Horrighs, A.; Arner, P.; Eckel, J. Chemerin is a novel adipocyte-derived factor inducing insulin resistance in primary human skeletal muscle cells. Diabetes 2009, 58, 2731-2740. [CrossRef] [PubMed]

8. Yamauchi, T.; Kamon, J.; Minokoshi, Y.; Ito, Y.; Waki, H.; Uchida, S.; Yamashita, S.; Noda, M.; Kita, S.; Ueki, K.; et al. Adiponectin stimulates glucose utilization and fatty-acid oxidation by activating AMP-activated protein kinase. Nat. Med. 2002, 8, 1288-1295. [CrossRef] [PubMed]

9. Tanyanskiy, D.A.; Martynikhin, I.A.; Rotar, O.P.; Konradi, A.O.; Sokolian, N.A.; Neznanov, N.G.; Denisenko, A.D. Association of adipokines with metabolic disorders in patients with schizophrenia: Results of comparative study with mental healthy cohort. Diabetes Metab. Syndr. Clin. Res. Rev. 2015, 9, 163-167. [CrossRef] [PubMed] 
10. De Souza Batista, C.M.; Yang, R.Z.; Lee, M.J.; Glynn, N.M.; Yu, D.Z.; Pray, J.; Ndubuizu, K.; Patil, S.; Schwartz, A.; Kligman, M.; et al. Omentin plasma levels and gene expression are decreased in obesity. Diabetes 2007, 56, 1655-1661. [CrossRef] [PubMed]

11. Ceddia, R.B.; Koistinen, H.A.; Zierath, J.R.; Sweeney, G. Analysis of paradoxical observations on the association between leptin and insulin resistance. FASEB J. 2002, 16, 1163-1176. [CrossRef] [PubMed]

12. Mantzoros, C.S.; Magkos, F.; Brinkoetter, M.; Sienkiewicz, E.; Dardeno, T.A.; Kim, S.-Y.; Hamnvik, O.-P.R.; Koniaris, A. Leptin in human physiology and pathophysiology. AJP Endocrinol. Metab. 2011, 301, E567-E584. [CrossRef] [PubMed]

13. Revollo, J.R.; Körner, A.; Mills, K.F.; Satoh, A.; Wang, T.; Garten, A.; Dasgupta, B.; Sasaki, Y.; Wolberger, C.; Townsend, R.R.; et al. Nampt/PBEF/Visfatin Regulates Insulin Secretion in $\beta$ Cells as a Systemic NAD Biosynthetic Enzyme. Cell Metab. 2007, 6, 363-375. [CrossRef] [PubMed]

14. Chang, Y.H.; Chang, D.M.; Lin, K.C.; Shin, S.J.; Lee, Y.J. Visfatin in overweight/obesity, type 2 diabetes mellitus, insulin resistance, metabolic syndrome and cardiovascular diseases: A meta-analysis and systemic review. Diabetes Metab. Res. Rev. 2011, 27, 515-527. [CrossRef] [PubMed]

15. Heiker, J.T. Vaspin (serpinA12) in obesity, insulin resistance, and inflammation. J. Pept. Sci. 2014, 20, $299-306$. [CrossRef] [PubMed]

16. Boucher, J.; Masri, B.; Daviaud, D.; Gesta, S.; Guigné, C.; Mazzucotelli, A.; Castan-Laurell, I.; Tack, I.; Knibiehler, B.; Carpéné, C.; et al. Apelin, a newly identified adipokine up-regulated by insulin and obesity. Endocrinology 2005, 146, 1764-1771. [CrossRef] [PubMed]

17. Bertrand, C.; Valet, P.; Castan-Laurell, I. Apelin and energy metabolism. Front. Physiol. 2015, 6, 115. [CrossRef] [PubMed]

18. Pedersen, B.K. Muscles and their myokines. J. Exp. Biol. 2011, 214, 337-346. [CrossRef] [PubMed]

19. Jedrychowski, M.P.; Wrann, C.D.; Paulo, J.A.; Gerber, K.K.; Szpyt, J.; Robinson, M.M.; Nair, K.S.; Gygi, S.P.; Spiegelman, B.M. Detection and quantitation of circulating human irisin by tandem mass spectrometry. Cell Metab. 2015, 22, 734-740. [CrossRef] [PubMed]

20. Quinn, L.S.; Anderson, B.G.; Strait-Bodey, L.; Stroud, A.M.; Argiles, J.M. Oversecretion of interleukin-15 from skeletal muscle reduces adiposity. AJP Endocrinol. Metab. 2008, 296, E191-E202. [CrossRef] [PubMed]

21. Boström, P.; Wu, J.; Jedrychowski, M.P.; Korde, A.; Ye, L.; Lo, J.C.; Rasbach, K.A.; Boström, E.A.; Choi, J.H.; Long, J.Z.; et al. A PGC1- $\alpha$-dependent myokine that drives brown-fat-like development of white fat and thermogenesis. Nature 2012, 481, 463-468. [CrossRef] [PubMed]

22. Roberts, L.D.; Boström, P.; O'Sullivan, J.F.; Schinzel, R.T.; Lewis, G.D.; Dejam, A.; Lee, Y.K.; Palma, M.J.; Calhoun, S.; Georgiadi, A.; et al. $\beta$-Aminoisobutyric acid induces browning of white fat and hepatic $\beta$-oxidation and is inversely correlated with cardiometabolic risk factors. Cell Metab. 2014, 19, 96-108. [CrossRef] [PubMed]

23. Jung, T.W.; Hwang, H.J.; Hong, H.C.; Yoo, H.J.; Baik, S.H.; Choi, K.M. BAIBA attenuates insulin resistance and inflammation induced by palmitate or a high fat diet via an AMPK-PPAR $\delta$-dependent pathway in mice. Diabetologia 2015, 58, 2096-2105. [CrossRef] [PubMed]

24. Shi, C.; Zhao, M.; Shu, X.; Xiong, X.; Wang, J. $\beta$-aminoisobutyric acid attenuates hepatic endoplasmic reticulum stress and glucose / lipid metabolic disturbance in mice with type 2 diabetes. Sci. Rep. 2016, 6, 21924. [CrossRef] [PubMed]

25. Crumpler, H.R.; Dent, C.E.; Harris, H.; Westall, R.G. $\beta$-aminoisobutyric acid ( $\alpha$-methyl- $\beta$-alanine): A new amino-acid obtained from human urine. Nature 1951, 167, 307-308. [CrossRef] [PubMed]

26. Solem, E.; Jellum, E.; Eldjarn, L. The absolute configuration of $\beta$-aminoisobutyric acid in human serum and urine. Clin. Chim. Acta 1974, 50, 393-403. [CrossRef]

27. Vemula, H.; Kitase, Y.; Ayon, N.J.; Bonewald, L.; Gutheil, W.G. Gaussian and linear deconvolution of LC-MS/MS chromatograms of the eight aminobutyric acid isomers. Anal. Biochem. 2017, 516, 75-85. [CrossRef] [PubMed]

28. Van Gennip, A.H.; Kamerling, J.P.; de Bree, P.K.; Wadman, S.K. Linear relationship between the R- and S-enantiomers of $\beta$-aminoisobutyric acid in human urine. Clin. Chim. Acta 1981, 116, 261-267. [CrossRef]

29. Mo, C.; Wang, Z.; Bian, L.; Isaacson, J.; Recker, R.; Lappe, J.; Bonewald, L.; Brotto, M. A Direct LC-MS/MS Method for the Simultaneous Quantification of Isomeric Aminobutyric Acids in Biological Fluids and Its Application in Bone-Muscle Studies. In Proceedings of the 2018 Annual Meeting of the American Society for Bone and Mineral Research, Montréal, QC, Canada, 28 September-1 October 2018; p. 213. 
30. Fink, K.; Cline, R.; Henderson, R.; Fink, R. Metabolism of thymine by rat liver in vitro. J. Biol. Chem. 1956, 221, 425-433. [PubMed]

31. Kontani, Y.; Kaneko, M.; Kikugawa, M.; Fujimoto, S.; Tamaki, N. Identity of D-3-aminoisobutyrate-pyruvate aminotransferase with alanine-glyoxylate aminotransferase 2. BBA-Gen. Subj. 1993, 1156, 161-166. [CrossRef]

32. Lee, I.S.M.; Nishikimi, M.; Inoue, M.; Muragaki, Y.; Ooshima, A. Specific expression of alanine-glyoxylate aminotransferase 2 in the epithelial cells of Henle's loop. Nephron 1999, 83, 184-185. [CrossRef] [PubMed]

33. Kittel, A.; Maas, R.; König, J.; Mieth, M.; Weiss, N.; Jarzebska, N.; Hohenstein, B.; Martens-lobenhoffer, J.; Bode-böger, S.M.; Rodionov, R.N. Biochemical and Biophysical Research Communications In vivo evidence that Agxt2 can regulate plasma levels of dimethylarginines in mice. Biochem. Biophys. Res. Commun. 2013, 430, 84-89. [CrossRef] [PubMed]

34. Rodionov, R.N.; Jarzebska, N.; Weiss, N.; Lentz, S.R. AGXT2: A promiscuous aminotransferase. Trends Pharmacol. Sci. 2014, 35, 575-582. [CrossRef] [PubMed]

35. Pollitt, R.J.; Green, A.; Smith, R. Excessive excretion of beta-alanine and of 3-hydroxypropionic, R- and S-3-aminoisobutyric, R- and S-3-hydroxyisobutyric and S-2-(hydroxymethyl)butyric acids probably due to a defect in the metabolism of the corresponding malonic semialdehydes. J. Inherit. Metab. Dis. 1985, 8, 75-79. [CrossRef] [PubMed]

36. Roe, C.R.; Struys, E.; Kok, R.M.; Roe, D.S.; Harris, R.A.; Jakobs, C. Methylmalonic Semialdehyde Dehydrogenase Deficiency: Psychomotor Delay and Methylmalonic Aciduria without Metabolic Decompensation. Mol. Genet. Metab. 1998, 65, 35-43. [CrossRef] [PubMed]

37. Kupiecki, F.P.; Coon, M.J. The enzymatic synthesis of beta-aminoisobutyrate, a product of valine metabolism, and of beta-alanine, a product of beta-hydroxypropionate metabolism. J. Biol. Chem. 1957, 229, 743-754. [PubMed]

38. Kakimoto, Y.; Kanazawa, A.; Taniguchi, K.; Sano, I. $\beta$-Aminoisobutyrate- $\alpha$-ketoglutarate transaminase in relation to $\beta$-aminoisobutyric aciduria. BBA-Gen. Subj. 1968, 156, 374-380. [CrossRef]

39. UniProtKB-P80404 (GABT_HUMAN). Available online: https://www.uniprot.org/uniprot/P80404 (accessed on 11 January 2019).

40. Fagerberg, L.; Hallström, B.M.; Oksvold, P.; Kampf, C.; Djureinovic, D.; Odeberg, J.; Habuka, M.; Tahmasebpoor, S.; Danielsson, A.; Edlund, K.; et al. Analysis of the Human Tissue-specific Expression by Genome-wide Integration of Transcriptomics and Antibody-based Proteomics. Mol. Cell. Proteom. 2014, 13, 397-406. [CrossRef] [PubMed]

41. Tamaki, N.; Kaneko, M.; Kikugawa, M.; Fujimoto, S. Evaluation of interconversion between (R)-and (S) -enantiomers of fl-aminoisobutyrate. BBA-Gen. Subj. 1990, 1035, 117-119. [CrossRef]

42. Suhre, K.; Wallaschofski, H.; Raffler, J.; Friedrich, N.; Haring, R.; Michael, K.; Wasner, C.; Krebs, A.; Kronenberg, F.; Chang, D.; et al. A genome-wide association study of metabolic traits in human urine. Nat. Genet. 2011, 43, 565-569. [CrossRef] [PubMed]

43. Kittel, A.; Müller, F.; König, J.; Mieth, M.; Sticht, H.; Zolk, O.; Kralj, A.; Heinrich, M.R.; Fromm, M.F.; Maas, R. Alanine-glyoxylate aminotransferase 2 (AGXT2) polymorphisms have considerable impact on methylarginine and $\beta$-aminoisobutyrate metabolism in healthy volunteers. PLoS ONE 2014, 9, e88544. [CrossRef] [PubMed]

44. Yanai, J.; Kakimoto, Y.; Tsujio, T.; Sano, I. Genetic study of beta-aminoisobutyric acid excretion by Japanese. Am. J. Hum. Genet. 1969, 21, 115-132. [PubMed]

45. Kitase, Y.; Vallejo, J.A.; Gutheil, W.; Vemula, H.; Jähn, K.; Yi, J.; Zhou, J.; Brotto, M.; Bonewald, L.F. $\beta$-aminoisobutyric Acid, L-BAIBA, Is a Muscle-Derived Osteocyte Survival Factor. Cell Rep. 2018, 22, 1531-1544. [CrossRef] [PubMed]

46. Note, R.; Maisonneuve, C.; Lette, P.; Peytavin, G.; Djouadi, F.; Igoudjil, A.; Guimont, M.; Biour, M.; Pessayre, D.; Fromenty, B. Mitochondrial and Metabolic Effects of Nucleoside Reverse Transcriptase Inhibitors (NRTIs) in Mice Receiving One of Five Single- and Three Dual-NRTI Treatments. Antimicrob. Agents Chemother. 2003, 47, 3384-3392. [CrossRef] [PubMed]

47. Podzamczer, D.; Ferrer, E.; Sanchez, P.; Gatell, J.M.; Crespo, M.; Fisac, C.; Lonca, M.; Sanz, J.; Niubo, J.; Veloso, S.; et al. Less Lipoatrophy and Better Lipid Profile with Abacavir as Compared to Stavudine. JAIDS J. Acquir. Immune Defic. Syndr. 2007, 44, 139-147. [CrossRef] [PubMed] 
48. Maisonneuve, C.; Igoudjil, A.; Begriche, K.; Lettéron, P.; Guimont, M.-C.; Bastin, J.; Laigneau, J.-P.; Pessayre, D.; Fromenty, B. Effects of zidovudine, stavudine and beta-aminoisobutyric acid on lipid homeostasis in mice: Possible role in human fat wasting. Antivir. Ther. 2004, 9, 801-810. [PubMed]

49. Begriche, K.; Massart, J.; Abbey-toby, A.; Igoudjil, A.; Lettéron, P.; Fromenty, B. $\beta$-Aminoisobutyric Acid Prevents Diet-induced Obesity in Mice with Partial Leptin Deficiency. Obesity 2008, 16, 2053-2067. [CrossRef] [PubMed]

50. Desvergne, B.; Michalik, L.; Wahli, W. Transcriptional Regulation of Metabolism. Physiol. Rev. 2006, 86, 465-514. [CrossRef] [PubMed]

51. Bartelt, A.; Bruns, O.T.; Reimer, R.; Hohenberg, H.; Ittrich, H.; Peldschus, K.; Kaul, M.G.; Tromsdorf, U.I.; Weller, H.; Waurisch, C.; et al. Brown adipose tissue activity controls triglyceride clearance. Nat. Med. 2011, 17, 200-205. [CrossRef] [PubMed]

52. Viollet, B.; Guigas, B.; Leclerc, J.; Hébrard, S.; Lantier, L.; Mounier, R.; Andreelli, F.; Foretz, M. AMP-activated protein kinase in the regulation of hepatic energy metabolism: From physiology to therapeutic perspectives. Acta Physiol. (Oxf). 2009, 196, 81-98. [CrossRef] [PubMed]

53. Li, Y.; Xu, S.; Mihaylova, M.M.; Zheng, B.; Hou, X.; Jiang, B.; Park, O.; Luo, Z.; Lefai, E.; Shyy, J.Y.-J.; et al. AMPK Phosphorylates and Inhibits SREBP Activity to Attenuate Hepatic Steatosis and Atherosclerosis in Diet-Induced Insulin-Resistant Mice. Cell Metab. 2011, 13, 376-388. [CrossRef] [PubMed]

54. Ozcan, U.; Cao, Q.; Yilmaz, E.; Lee, A.-H.; Iwakoshi, N.N.; Ozdelen, E.; Tuncman, G.; Görgün, C.; Glimcher, L.H.; Hotamisligil, G.S. Endoplasmic Reticulum Stress Links Obesity, Insulin Action, and Type 2 Diabetes. Science 2004, 306, 457-461. [CrossRef] [PubMed]

55. Vergès, B. Abnormal hepatic apolipoprotein B metabolism in type 2 diabetes. Atherosclerosis 2010, 211, 353-360. [CrossRef] [PubMed]

56. Jung, T.W.; Park, H.S.; Choi, G.H.; Kim, D.; Lee, T. $\beta$-aminoisobutyric acid attenuates LPS-induced inflammation and insulin resistance in adipocytes through AMPK-mediated pathway. J. Biomed. Sci. 2018, 25, 27. [CrossRef] [PubMed]

57. Havel, P.J. Update on adipocyte hormones: Regulation of energy balance and carbohydrate/lipid metabolism. Diabetes 2004, 53 (Suppl. S1), S143-S151. [CrossRef]

58. Friedman, J.M.; Halaas, J.L. Leptin and the regulation of body weight in mammals. Nature 1998, 395, 763-770. [CrossRef] [PubMed]

59. Haynes, W.G. Interaction between leptin and sympathetic nervous system in hypertension. Curr. Hypertens. Rep. 2000, 2, 311-318. [CrossRef] [PubMed]

60. Rayner, D.V.; Trayhurn, P. Regulation of leptin production: Sympathetic nervous system interactions. J. Mol. Med. 2001, 79, 8-20. [CrossRef] [PubMed]

61. Maeda, N.; Takahashi, M.; Funahashi, T.; Kihara, S.; Nishizawa, H.; Kishida, K.; Nagaretani, H.; Matsuda, M.; Komuro, R.; Ouchi, N.; et al. PPAR $\gamma$ Ligands Increase Expression and Plasma Concentrations of Adiponectin, an Adipose-Derived Protein. Diabetes 2001, 50, 2094-2099. [CrossRef] [PubMed]

62. Weisberg, S.P.; McCann, D.; Desai, M.; Rosenbaum, M.; Leibel, R.L.; Ferrante, A.W. Obesity is associated with macrophage accumulation in adipose tissue. J. Clin. Investig. 2003, 112, 1796-1808. [CrossRef] [PubMed]

63. Lee, W.; Yun, S.; Choi, G.H.; Jung, T.W. BAIBA Attenuates the Expression of Inflammatory Cytokines and Attachment Molecules and ER Stress in HUVECs and THP-1 Cells. Pathobiology 2018, 85, 280-288. [CrossRef] [PubMed]

64. He, Y.; Lu, L.; Wei, X.; Jin, D.; Qian, T.; Yu, A.; Sun, J.; Cui, J.; Yang, Z. The multimerization and secretion of adiponectin are regulated by TNF-alpha. Endocrine 2016, 51, 456-468. [CrossRef] [PubMed]

65. Uno, M.; Nishimura, S.; Fukuchi, K.; Kaneta, Y.; Oda, Y.; Komori, H.; Takeda, S.; Haga, T.; Agatsuma, T.; Nara, F. Identification of physiologically active substances as novel ligands for MRGPRD. J. Biomed. Biotechnol. 2012, 2012, 816159. [CrossRef] [PubMed]

66. Schmieden, V.; Betz, H. Pharmacology of the inhibitory glycine receptor: Agonist and antagonist actions of amino acids and piperidine carboxylic acid compounds. Mol. Pharmacol. 1995, 48, 919-927. [PubMed]

67. Horikoshi, T.; Asanuma, A.; Yanagisawa, K.; Anzai, K.; Goto, S. Taurine and $\beta$-alanine act on both GABA and glycine receptors in Xenopus oocyte injected with mouse brain messenger RNA. Mol. Brain Res. 1988, 4, 97-105. [CrossRef] 
68. Shinohara, T.; Harada, M.; Ogi, K.; Maruyama, M.; Fujii, R.; Tanaka, H.; Fukusumi, S.; Komatsu, H.; Hosoya, M.; Noguchi, Y.; et al. Identification of a G protein-coupled receptor specifically responsive to beta-alanine. J. Biol. Chem. 2004, 279, 23559-23564. [CrossRef] [PubMed]

69. Brown, A.J.; Goldsworthy, S.M.; Barnes, A.A.; Eilert, M.M.; Tcheang, L.; Daniels, D.; Muir, A.I.; Wigglesworth, M.J.; Kinghorn, I.; Fraser, N.J.; et al. The Orphan G Protein-coupled Receptors GPR41 and GPR43 Are Activated by Propionate and Other Short Chain Carboxylic Acids. J. Biol. Chem. 2003, 278, 11312-11319. [CrossRef] [PubMed]

70. Xiong, Y.; Miyamoto, N.; Shibata, K.; Valasek, M.A.; Motoike, T.; Kedzierski, R.M.; Yanagisawa, M. Short-chain fatty acids stimulate leptin production in adipocytes through the $\mathrm{G}$ protein-coupled receptor GPR41. Proc. Natl. Acad. Sci. USA 2004, 101, 1045-1050. [CrossRef] [PubMed]

71. Van den Eynden, J. Glycine and glycine receptor signalling in non-neuronal cells. Front. Mol. Neurosci. 2009, 2, 9. [CrossRef] [PubMed]

72. Hafidi, M.E. Glycine intake decreases plasma free fatty acids, adipose cell size, and blood pressure in sucrose-fed rats. AJP Regul. Integr. Comp. Physiol. 2004, 287, R1387-R1393. [CrossRef] [PubMed]

73. Gannon, M.C.; Nuttall, J.A.; Nuttall, F.Q. The metabolic response to ingested glycine. Am. J. Clin. Nutr. 2002, 76, 1302-1307. [CrossRef] [PubMed]

74. Erlitzki, R.; Gong, Y.; Zhang, M.; Minuk, G. Identification of gamma-aminobutyric acid receptor subunit types in human and rat liver. Am. J. Physiol. Gastrointest. Liver Physiol. 2000, 279, G733-G739. [CrossRef] [PubMed]

75. Akinci, M.K.; Schofield, P.R. Widespread expression of GABA(A) receptor subunits in peripheral tissues. Neurosci. Res. 1999, 35, 145-153. [CrossRef]

76. Bhat, R.; Axtell, R.; Mitra, A.; Miranda, M.; Lock, C.; Tsien, R.W.; Steinman, L. Inhibitory role for GABA in autoimmune inflammation. Proc. Natl. Acad. Sci. USA 2010, 107, 2580-2585. [CrossRef] [PubMed]

77. Broer, S. Amino Acid Transport Across Mammalian Intestinal and Renal Epithelia. Physiol. Rev. 2008, 88, 249-286. [CrossRef] [PubMed]

78. Rodionov, R.N.; Oppici, E.; Martens-Lobenhoffer, J.; Jarzebska, N.; Brilloff, S.; Burdin, D.; Demyanov, A.; Kolouschek, A.; Leiper, J.; Maas, R.; et al. A Novel Pathway for Metabolism of the Cardiovascular Risk Factor Homoarginine by alanine:glyoxylate aminotransferase 2. Sci. Rep. 2016, 6, 35277. [CrossRef] [PubMed]

79. Sibal, L.; Agarwal, S.C.; Home, P.D.; Boger, R.H. The Role of Asymmetric Dimethylarginine (ADMA) in Endothelial Dysfunction and Cardiovascular Disease. Curr. Cardiol. Rev. 2010, 6, 82-90. [CrossRef] [PubMed]

80. Atzler, D.; Gore, M.O.; Ayers, C.R.; Choe, C.U.; Böger, R.H.; De Lemos, J.A.; McGuire, D.K.; Schwedhelm, E. Homoarginine and cardiovascular outcome in the population-based dallas heart study. Arterioscler. Thromb. Vasc. Biol. 2014, 34, 2501-2507. [CrossRef] [PubMed]

81. Stockebrand, M.; Hornig, S.; Neu, A.; Atzler, D.; Cordts, K.; Böger, R.H.; Isbrandt, D.; Schwedhelm, E.; Choe, C.U. Homoarginine supplementation improves blood glucose in diet-induced obese mice. Amino Acids 2015, 47, 1921-1929. [CrossRef] [PubMed]

82. Li, T.; Feng, R.; Zhao, C.; Wang, Y.; Wang, J.; Liu, S.; Cao, J.; Wang, H.; Wang, T.; Guo, Y.; et al. Dimethylarginine Dimethylaminohydrolase 1 Protects Against High-Fat Diet-Induced Hepatic Steatosis and Insulin Resistance in Mice. Antioxid. Redox Signal. 2017, 26, 598-609. [CrossRef] [PubMed]

83. Rhee, E.P.; Ho, J.E.; Chen, M.; Shen, D.; Cheng, S.; Larson, M.G.; Ghorbani, A.; Shi, X.; Helenius, I.T.; Donnell, C.J.O.; et al. Resource A Genome-wide Association Study of the Human Metabolome in a Community-Based Cohort. Cell Metab. 2013, 18, 130-143. [CrossRef] [PubMed]

84. Spitsyn, V.A.; Afanas'eva, I.S. Different Allele Frequencies of the BAIB Locus Determining Excretion of $\beta$-Aminoisobutyric Acid in Healthy Donors and Patients with Coronary Atherosclerosis from the Buryat and Lithuanian Populations. Russ. J. Genet. 2001, 37, 1444-1447. [CrossRef]

85. Yoshino, Y.; Kohara, K.; Abe, M.; Ochi, S.; Mori, Y.; Yamashita, K.; Igase, M.; Tabara, Y.; Mori, T.; Miki, T.; et al. Missense variants of the alanine: Glyoxylate aminotransferase 2 gene correlated with carotid atherosclerosis in the Japanese population. J. Biol. Regul. Homeost. Agents 2014, 28, 605-614. [PubMed]

86. Schulze, F.; Carter, A.M.; Schwedhelm, E.; Ajjan, R.; Maas, R.; von Holten, R.A.; Atzler, D.; Grant, P.J.; Böger, R.H. Symmetric dimethylarginine predicts all-cause mortality following ischemic stroke. Atherosclerosis 2010, 208, 518-523. [CrossRef] [PubMed] 
87. Pilz, S.; Meinitzer, A.; Tomaschitz, A.; Drechsler, C.; Ritz, E.; Krane, V.; Wanner, C.; Boehm, B.O.; März, W. Low homoarginine concentration is a novel risk factor for heart disease. Heart 2011, 97, 1222-1227. [CrossRef] [PubMed]

88. Seppälä, I.; Kleber, M.E.; Lyytikäinen, L.P.; Hernesniemi, J.A.; Mäkelä, K.M.; Oksala, N.; Laaksonen, R.; Pilz, S.; Tomaschitz, A.; Silbernagel, G.; et al. Genome-wide association study on dimethylarginines reveals novel AGXT2 variants associated with heart rate variability but not with overall mortality. Eur. Heart J. 2014, 35, 524-530. [CrossRef] [PubMed]

89. Lüneburg, N.; Lieb, W.; Zeller, T.; Chen, M.H.; Maas, R.; Carter, A.M.; Xanthakis, V.; Glazer, N.L.; Schwedhelm, E.; Seshadri, S.; et al. Genome-wide association study of 1-arginine and dimethylarginines reveals novel metabolic pathway for symmetric dimethylarginine. Circ. Cardiovasc. Genet. 2014, 7, 864-872. [CrossRef] [PubMed]

90. Seppala, I.; Kleber, M.E.; Bevan, S.; Lyytikainen, L.P.; Oksala, N.; Hernesniemi, J.A.; Makela, K.M.; Rothwell, P.M.; Sudlow, C.; Dichgans, M.; et al. Associations of functional alanine-glyoxylate aminotransferase 2 gene variants with atrial fibrillation and ischemic stroke. Sci. Rep. 2016, 6, 1-10. [CrossRef] [PubMed]

91. Fernandez-Marcos, P.J.; Auwerx, J. Regulation of PGC-1 $\alpha$, a nodal regulator of mitochondrial biogenesis. Am. J. Clin. Nutr. 2011, 93, 884-890. [CrossRef] [PubMed]

92. Mootha, V.K.; Lindgren, C.M.; Eriksson, K.F.; Subramanian, A.; Sihag, S.; Lehar, J.; Puigserver, P.; Carlsson, E.; Ridderstråle, M.; Laurila, E.; et al. PGC-1alpha-responsive genes involved in oxidative phosphorylation are coordinately downregulated in human diabetes. Nat. Genet. 2003, 34, 267-273. [CrossRef] [PubMed]

(C) 2019 by the authors. Licensee MDPI, Basel, Switzerland. This article is an open access article distributed under the terms and conditions of the Creative Commons Attribution (CC BY) license (http:/ / creativecommons.org/licenses/by/4.0/). 